\title{
Phenomenology of Ice Ages
}

\author{
Clive Best ${ }^{1}$ \\ ${ }^{1}$ Independent Scientist, Cambridge, UK \\ Correspondence: Clive Best, Independent Scientist, Cambridge, UK. E-mail: clive.best@gmail.com
}

Received: April 21, 2017

Accepted: June 11, 2017

Online Published: July 20, 2017

doi:10.5539/esr.v6n2p131

URL: https://doi.org/10.5539/esr.v6n2p131

\begin{abstract}
A parameterized fit to 5.3 million years of Benthic foram $\delta \mathrm{O}^{18}$ data is described, which quantifies the magnitude, phase, and variability of Milankowitz terms. The 41,000y obliquity cycle, and 100,000y ellipticity cycles are dominant, with interglacial periods correlated with large orbital ellipticity. Shorter regular warming peaks correlate with larger obliquity. The fit is then used to extrapolate forward in time implying that the earth will begin cooling in about 2000 years time, eventually entering another 70,000 year long glaciation. Possible causes resulting from effects in the tropics due to increased eccentricity, and to changes in albedo at large obliquity, are discussed.
\end{abstract}

Keywords: ice ages, paleoclimate, Benthic foram

\section{Introduction}

The exact cause and evolution of ice ages still remain a mystery (Raymo \& Huybers, 2008). The favoured hypothesis of how ice ages develop is that orbital changes which induce cooler summers in the Northern Hemisphere then lead to less summer melting of winter ice allowing a spread of glacial coverage. This effect is enhanced further through feedback from increased ice albedo, and falling levels of atmospheric $\mathrm{CO} 2$ and water vapor. Milankowitz originally proposed this hypothesis in 1930 (Milaokovitch, 1941). However the correlation between summer insolation at $60^{\circ} \mathrm{N}$ and glacial periods is not really that convincing (Houghton, 1994), and geological evidence shows that temperature changes were global with 2-3 degree changes occurring in the tropics (Hostetler \& Mix, 1999). Why did the Earth shift into an unstable climate with global oscillations of 4-5 degrees every 100,000 years? What is the cause of the large-scale recent glaciations? Milankowitz identified the 3 main orbital cycles effecting solar radiation intensity and distribution and several have reported their signal in proxy temperature data (Hays, Imbrie \& Shackleton, 1976).

The work presented in this paper does not attempt to explain the origin of the ice ages, but instead tries to parameterize the observed temperature dependencies and thereby derive quantitative information. This approach applied in other branches of physics is usually called phenomenology (Note 1).

\section{Data and Fits}

The "LRO4" data (Lisiecki \& Raymo, 2005) is a remarkable set of global proxy temperature data spanning a 5.3 million year period throughout the Pleistocene Ice Ages. It consists of a stack of 57 globally distributed benthic d18O records. Unlike the Vostok Ice core samples, which measure temperature at a single site in Antarctica, LRO4 represent the global temperature and should therefore be more representative of climate changes. The data are based on samples of deep-sea sediments consisting of calcium carbonate from plankton. The oxygen content $(\mathrm{CaCO} 3)$ consists of a small amount of $\mathrm{O} 18$ mixed with $\mathrm{O} 16$. The ratio of $\mathrm{O} 18$ to $\mathrm{O} 16$ increases slightly with cooler surface temperatures. This is because $\mathrm{O} 18$ is slightly heavier and evaporates less readily than $\mathrm{O} 16 . \delta^{18} \mathrm{O}$ is the ratio of O18/O16 compared to a standard Calcite value. LRO4 represents a global measure of this ratio from ocean sediments and can be directly related to prevailing temperatures at the time. It provides a unique overview of the onset of Ice Ages (Pleistocene Era) starting 5.3 million years ago.

In order to quantify the contribution of different Milankowitz cycles in LR04, the data were split into different time ranges and fitted to a linear sum of simple harmonics plus linear terms. The data fall naturally into 5 time periods based both on sampling rate and visible differences in signals. These periods are 1) 0-600 thousand ya 2) $600-900$ thousand ya 3) $900-1500$ thousand ya 4) $1500-3000$ thousand ya and 5) 3000-5300 thousand ya. The general form used in all fits with time $\mathrm{x}$ in units of 1000 years ago is 


$$
\delta^{18} \mathrm{O}=\mathbf{c o n s t}+\mathbf{a x}+\mathbf{b}^{*} \sin (2 \pi / \lambda 1 * \mathrm{x}-\mathbf{c})+\mathbf{d}^{*} \sin (2 \pi / / \lambda 2-\mathbf{e})+\mathbf{f}^{*} \sin (2 \pi / \lambda 3-\mathbf{g})
$$

A least squares fit was performed on each sub-set of data independently.

\section{$2.1600 \mathrm{kya}$}

For the last 600,000 year data there are clear oscillations present at 100,000 years and 41,000 years corresponding to the eccentricity changes of the Earth's orbit and the change in obliquity. Including a 23,000 years term made very little difference to $\chi^{2}$. It appears to have a negligible direct effect on Ice Ages. The best fit results were:

$$
\begin{gathered}
\delta \mathrm{O}^{18}=4.0+0.407 * \sin (0.0628 * \mathrm{x}-39.5)+0.259 * \sin (0.153 * \mathrm{x}-45.3) \\
\left(\chi^{2} / \mathrm{NDF}=39\right)
\end{gathered}
$$

\section{$2.2600-900 \mathrm{kya}$}

Before 600 kya a change is evident in the cycle of glaciations. The 41,000 year cycle is unchanged but the interval between successive Ice Ages has begun to shorten from 100,000 years. A better fit is found with a time period shortened to 84,000 years. The reason for this change is not clear. No 23,000 year signal is present, and the best fit found was

$$
\begin{gathered}
\delta \mathrm{O}^{18}=4.2+-0.36 * \sin (0.075 * \mathrm{x}-31.1)+0.29 * \sin (0.153 * \mathrm{x}+5.27) \\
\left(\chi^{2} / \mathrm{NDF}=19\right)
\end{gathered}
$$

Combining periods 1) and 2) both fits are compared to the data in Figure 1.

\section{$2.3900-1500 k y a$}

Big changes begin to be evident in the data earlier than 900,000 years. Between 900-1500 kya the 100,000 year cycle has almost disappeared leaving just the 41,000 year signal. The best fit found is

$$
\begin{gathered}
\delta^{18} \mathrm{O}=3.8+0.1 * \sin (0.0628 * \mathrm{x}+19.7)+0.25 * \sin (0.153 * \mathrm{x}+11) \\
\left(\chi \chi^{2} / \mathrm{NDF}=19\right)
\end{gathered}
$$

$2.41500-3000 \mathrm{kya}$

There is then a clear linear cooling trend from 3000 kya until 1500 kya where the only evident signal is the 41,000 year cycle. The best fit found was

$$
\begin{gathered}
\delta^{18} \mathrm{O}=4.0-0.00049 *(\mathrm{x}-1500)-0.17 * \sin (0.153 * \mathrm{x}-4.5)-0.006 * \sin (0.273 * \mathrm{x}-29.7) \\
\left(\chi^{2} / \mathrm{NDF}=9.8\right)
\end{gathered}
$$

The third term here is the 23,000 year precession term and the small amplitude demonstrates that it has a negligible effect. The combined fits from both periods are shown in figure 2.a

\section{$2.53000-5300 \mathrm{kya}$}

Finally the fit to data from 3000 to 5300 kya begins to show a longer 400,000 year eccentricity oscillation as well as $t 41,000$ year obliquity. The best fit found (see figure 3 ) was

$$
\begin{gathered}
\left.\delta^{18} \mathrm{O}=3.25-0.0002 *(\mathrm{x}-3000)-0.03 * \sin (0.015 *(\mathrm{x}-3000)-49.6)+0.07 * \sin (0.153 *(\mathrm{x}-3000)-31.3)\right) \\
\left(\chi^{2} / \mathrm{NDF}=6.2\right)
\end{gathered}
$$

Finally the full 5.3 million years of global temperature data and fits is shown in figure 5. Several proposals have been given as to the cause of the long term cooling trend. Antarctica has drifted over the last 5 million years to fully cover the South Pole, isolating warming from southern oceans and lowering the Earth's albedo. Another proposal is that the slow rise of the Tibetan plateau led to increases in ice cover at low latitudes further reducing net albedo (Raymo, Ruddiman, \& Froelich, 1988). A third proposal is that the closing of the Panama Isthmus 3 million years ago altered the flow of heat in the oceans resulting in the Atlantic Gulf stream (Haug \& Tiedemann, 1998). This then brought moist air to the Polar Regions resulting in increased snow and thicker ice. The Earth's climate appears currently to be in a highly unstable state, with saw-tooth like oscillations occurring every 100,000 years switching state from long glaciations to shorter warm inter-glacial periods lasting 10-20,000 years. The fits described above assume simple harmonic structure, which cannot describe such saw-tooth oscillations. However they do describe long-term trends and demonstrate that the underlying drivers are cycles of eccentricity and obliquity. The details of this correlation are surprising.

For the last 600,000 years Ice Ages have followed a 100,000 year cycle. Every inter-glacial period has been in phase with a maximum in the orbital eccentricity. This may seem counter-intuitive since ellipticity accentuates 
the variation in solar energy throughout the year. Unlike Ice core data, the LR04 data are global and represent changes in global energy balance. Between 600-900 million years ago the duration of Ice Ages seems to have shortened slightly to 84,000 year cycle and earlier than 900 Mya disappeared completely. It is as if the long term cooling trend needed to reach a threshold for the orbital eccentricity oscillation to kick in.

The second clear observation is that the 41,000 year cycle in the angle of rotation of the Earth to the orbital plain (obliquity) has had the longest term effect on climate for at least the last 5 million years. Surprisingly again, the larger the tilt angle the warmer the climate, as shown in figure 4. A larger obliquity also causes larger extremes in summer and winter temperatures, and both the Arctic Circle and the Tropics increase in spatial extent.

\section{Extrapolation to Next Glaciation}

Although the overall fit to 5.3 million years of proxy temperature data is not perfect it does reproduce the main features of the observed data. In particular the recurrence of Ice Ages over the last 600,000 years is well represented by the fit. Therefore the results can be used with reasonable confidence to extrapolate forward to the next major glaciation. This extrapolation is shown in Figure 6.

Within 10,000 years time the Earth will have begun a new deep glaciation, which should then peak in 30,000 years time.

\section{Climatic Effects of Ellipticity and Obliquity}

For the last 1 million years regular glaciations and warm interglacial periods have characterized the climate on Earth. The 100,000 year cycle of glaciations has been shown to be in phase with the variation in the ellipticity of the earth's orbit. A secondary temperature oscillation is also apparent which is in phase with the 41,000 year variation of the tilt in the axis of rotation. Possible causal explanations for this correlation are discussed in this section. Figure 7 shows the variation in sun earth distance with ellipticity.

In polar coordinates with the origin at a focal point, the equation of an ellipse can be written:

$$
\mathrm{r}(\theta)=\mathrm{a}\left(1-\varepsilon^{2}\right) /(1+\varepsilon \cos \theta)
$$

For planetary orbits the semi-major axis remains constant, which for a circular orbit is just the radius R. Conservation of angular momentum ensures that the total annual radiation flux is almost invariant of the ellipticity because the ratio of the angular velocity to a circular orbit is $\mathrm{R}^{2} / \mathrm{r}^{2}$. However the variation of solar radiation within the year varies dramatically as shown in Figure 7 calculated using $\left.S=S^{\circ}(1+\varepsilon \cos \theta)\right)^{2} /\left(\mathrm{R}^{2}\left(1-\varepsilon^{2}\right)\right)$, where $S^{\circ}$ is the solar constant. The annual insolation does slightly increase by the factor $\left(1-\varepsilon^{2}\right)^{-1 / 2}$ (Berger \& Loutre)

The extremes in incident radiation between aphelion and perihelion vary from $15 \%$ for $\varepsilon=0.058$ to $2 \%$ for $\varepsilon=0.005$ with $6.4 \%$ currently. These oscillations in solar heating are independent of seasons, although currently the perihelion coincides with summer in the southern hemisphere also being 7.8 days shorter than winter. In the tropics the variation in orbital solar intensity is likely to be most apparent giving rise to "orbital seasons". 17,000 years ago the asymmetry in insolation at the equator between equinoxes was $10 \%$ (Berger, Loutre, \& Melice, 2006). This effect may also be apparent in equatorial sea surface temperatures (Ashkenazy et al., 2010). Changes in tropical ocean heat distribution effects global climate (el Nino).

The tilt angle of the earth's axis to the ecliptic varies between $22.1^{\circ}$ and $24.5^{\circ}$ with a period of 41,000 years. This results in an increase in the size of the tropics (Cancer to Capricorn) and of the Arctic/Antarctic circles. The bulk of earth's heat is stored in the oceans, with the southern hemisphere dominating. The tropic of Capricorn moves south by about $370 \mathrm{~km}$ one cycle increasing tropical oceans by 9.8 million $\mathrm{km} 2$, representing $2 \%$ of the Earth's surface. The effect of this on the total albedo of the earth can be estimated using measurements made by CERES (Weilicki et al., 1996).

Albedo differences between tropical and sub-tropical ocean vary from about 0.3 to 0.1 . Therefore the net increase of a larger tropical ocean on global albedo is estimated at up to 0.006 (3\% of 0.2$)$. Taking an annual average of solar radiation as about $500 \mathrm{watts} / \mathrm{m} 2$ for the tropics infers an extra radiative forcing of $3 \mathrm{watts} / \mathrm{m} 2$. This would then cause approximately $1^{\circ} \mathrm{K}$ variation in average surface using a Stefan Boltzman response.

There appears to be a small delay between the maximum of obliquity and the response in proxy temperature from $\delta \mathrm{O}^{18}$. The last two interglacial transitions have occurred when both the ellipticity and obliquity were in maximum phase together.

\section{Discussion}

A fit to 5.3 million years of Benthic foram dO18 data quantifies the relative importance of different Milankowitz 
cycles. During the last million years the 100,000 year variation in the orbital ellipticity has been the main driver of interglacial periods. A secondary 41,000 year signal due to variations in the tilt of the Earth's rotation axis is evident for over 5 million years. No significant signal arising from the 23,000 year precession of the rotation axis is found. A 400,000year cycle modulation of ellipticity intensity is found 2.5 million years ago. An underlying linear cooling trend lasting 2 million years appears to have induced severe glaciations in phase with 100,000 year changes in ellipticity. The next major glaciation is predicted to begin as early as 2000 years time and no later than 10,000 years time, lasting for a further 70,000 years. Significant variations in tropical heat distribution due to orbital eccentricity must affect global climate. A possible explanation for the observed 41,000 year obliquity signal is that the resultant extension of tropical oceans changes global albedo leading to $\mathrm{a} \sim 1^{\circ} \mathrm{C}$ net increase in average surface temperatures. There are also non-linear saw-tooth oscillations in the historical temperature data, which remain unexplained. These may be related to internal climate feedbacks.

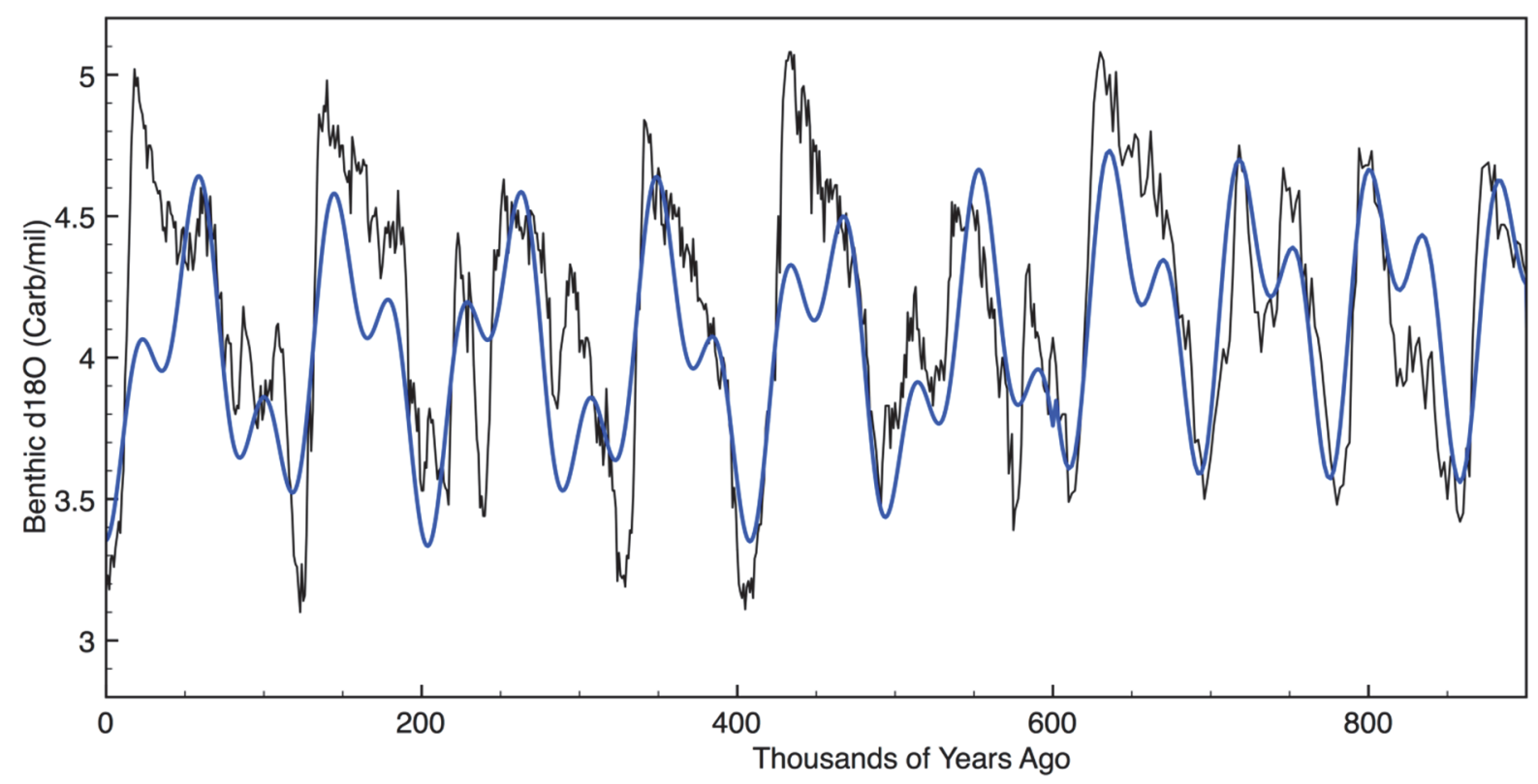

Figure 1. Combined fit results to 900,000 ya

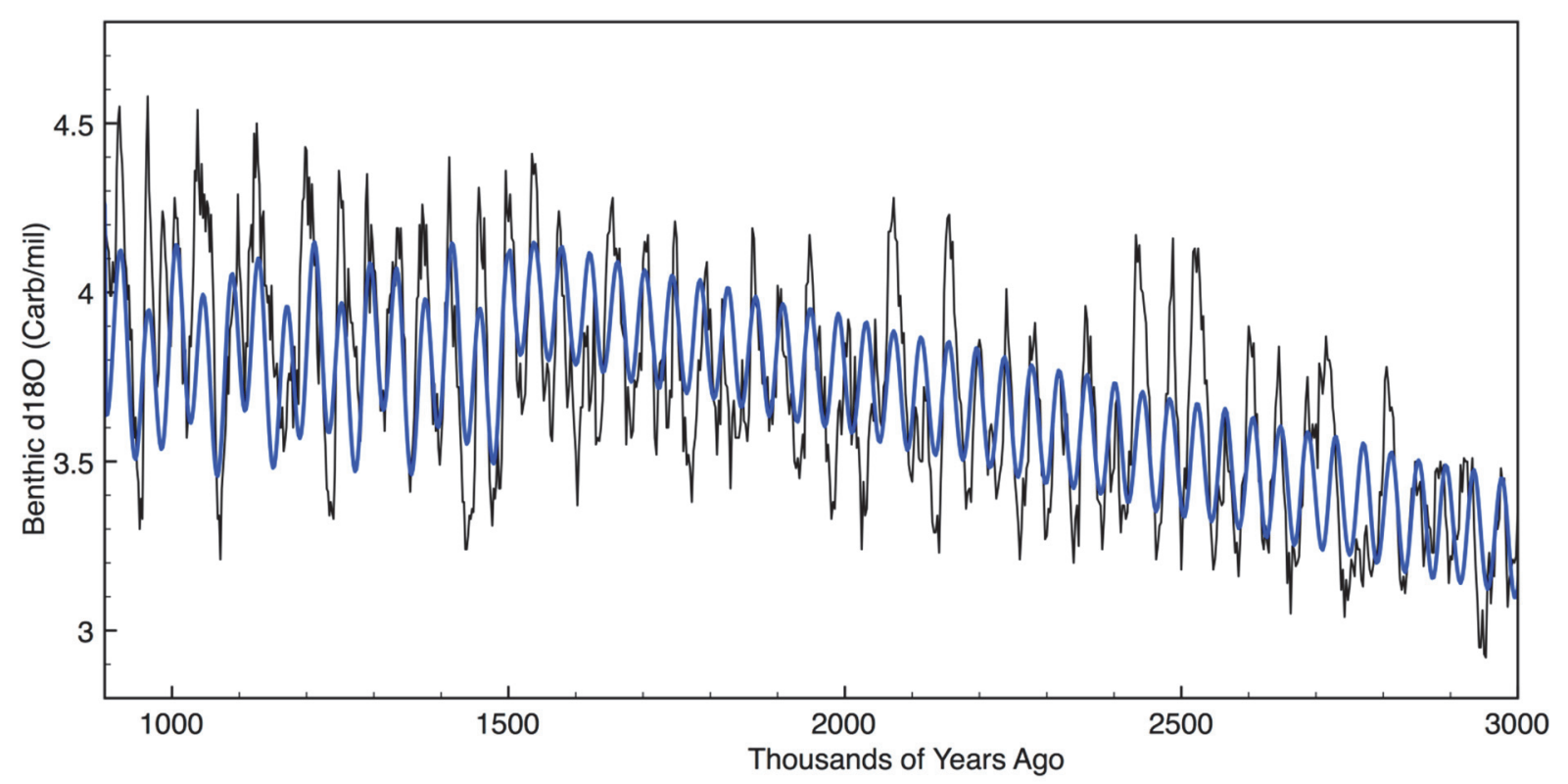

Figure 2. Combined fits compared to data 900-3000 


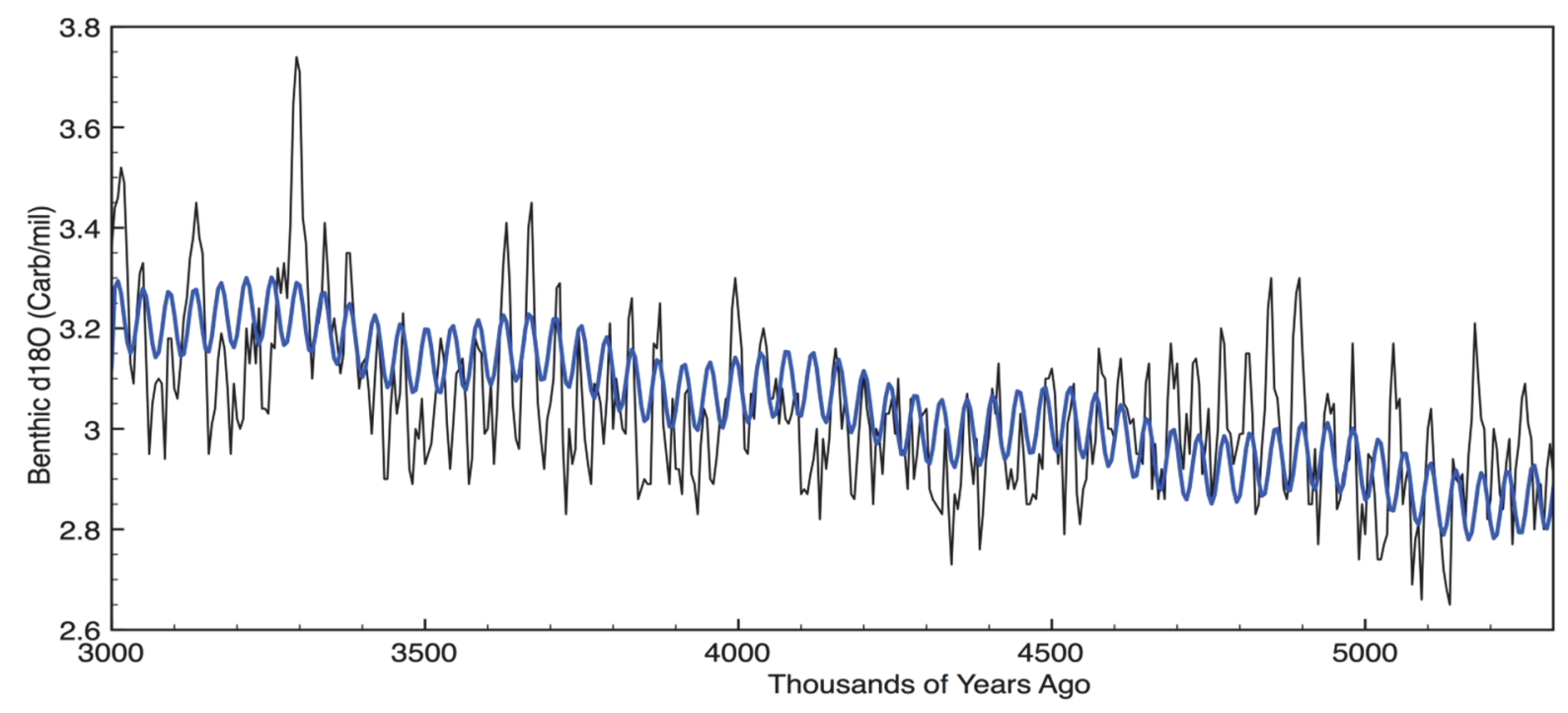

Figure 3. Evidence of a 400,000 year ellipticity oscillation 3000-53000 ya

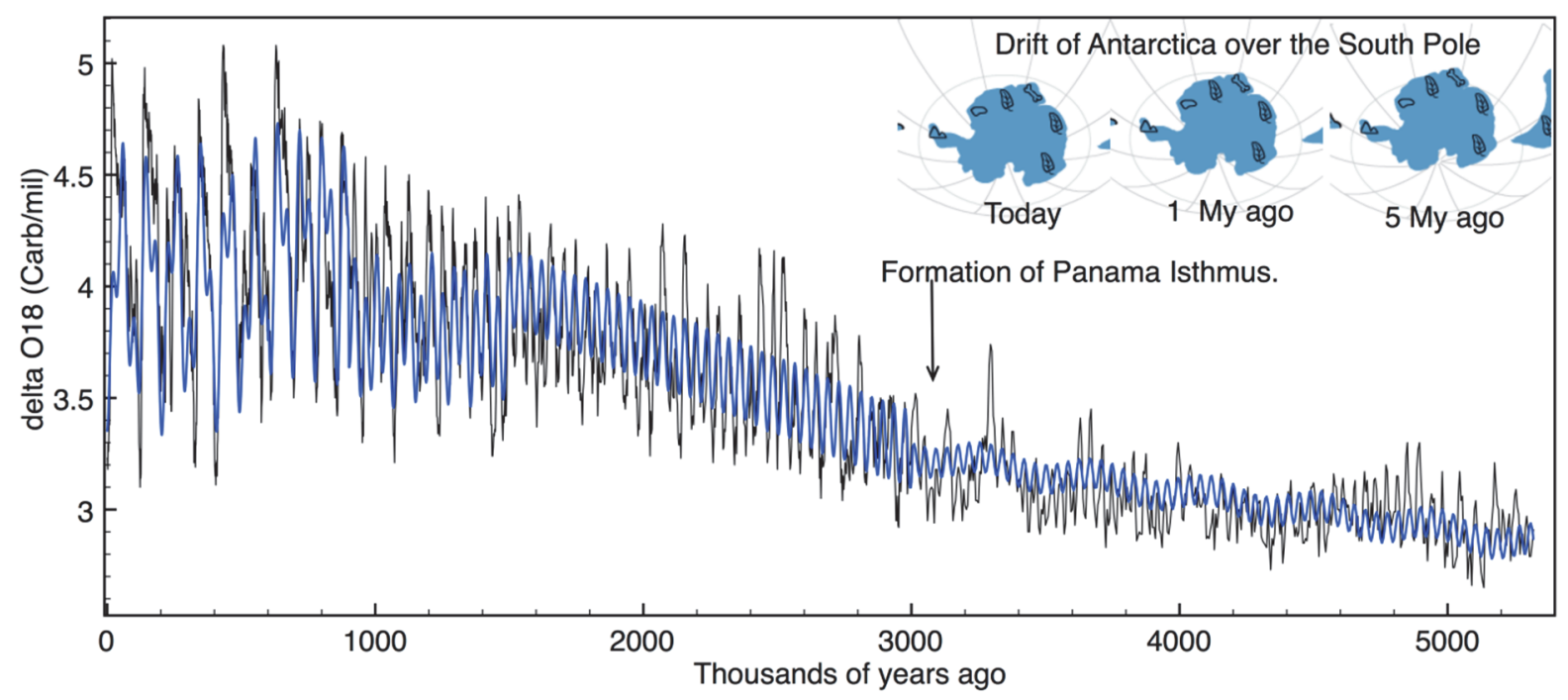

Figure 4. The full time series with overlaid fit results 


\section{a) Correlation of interglacials with orbital eccentricity}

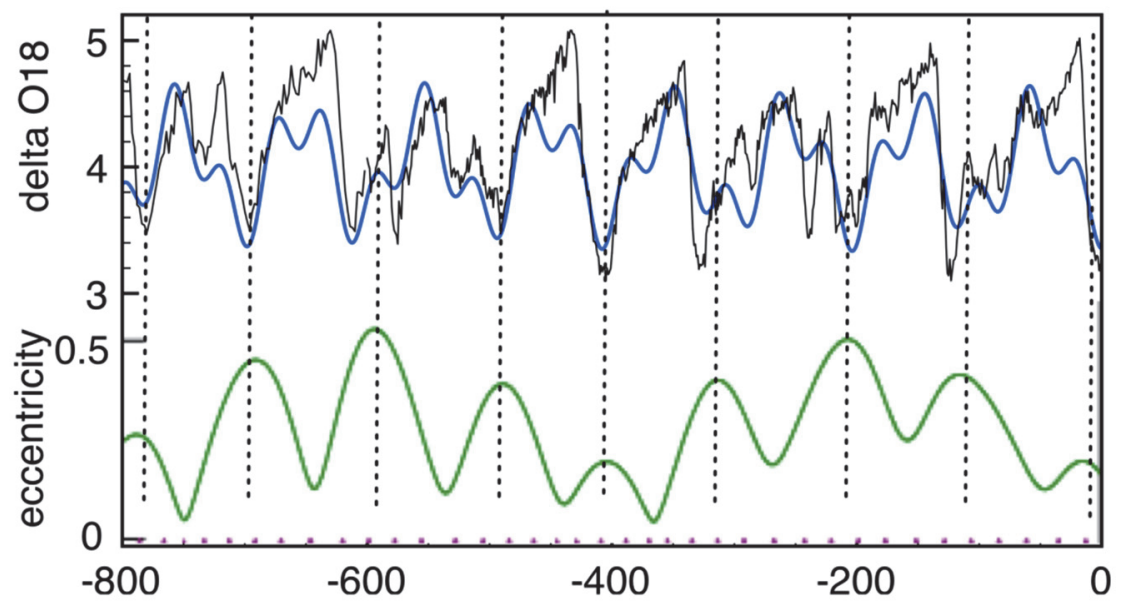

b) Correlation of interglacials with obliquity

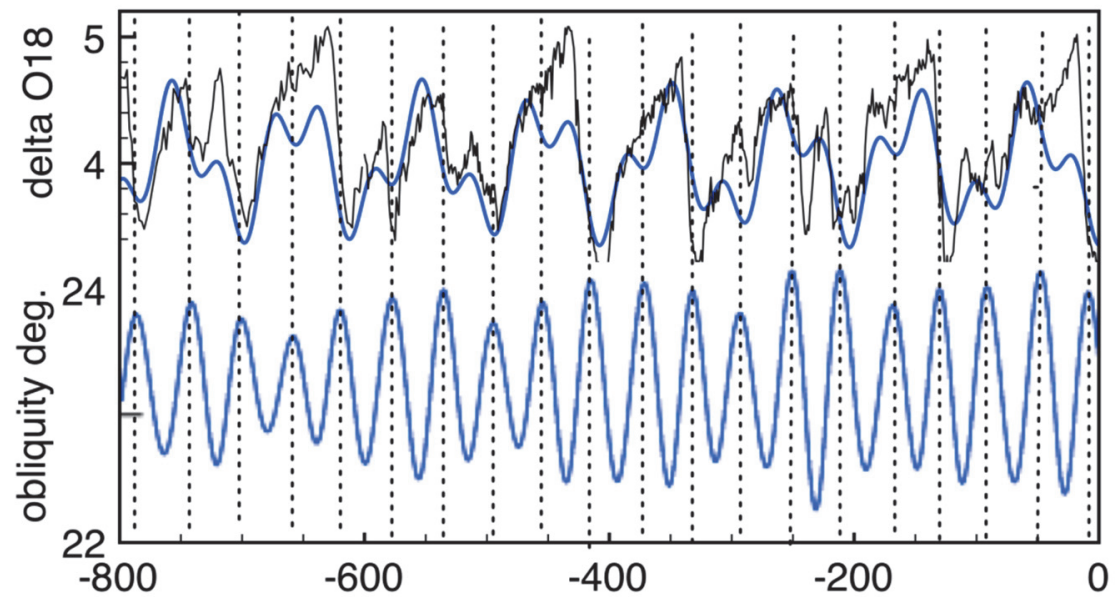

Figure 5. Correlation of a) ellipticity and b) obliquity with glaciation cycles over the last $800,000 \mathrm{y}$

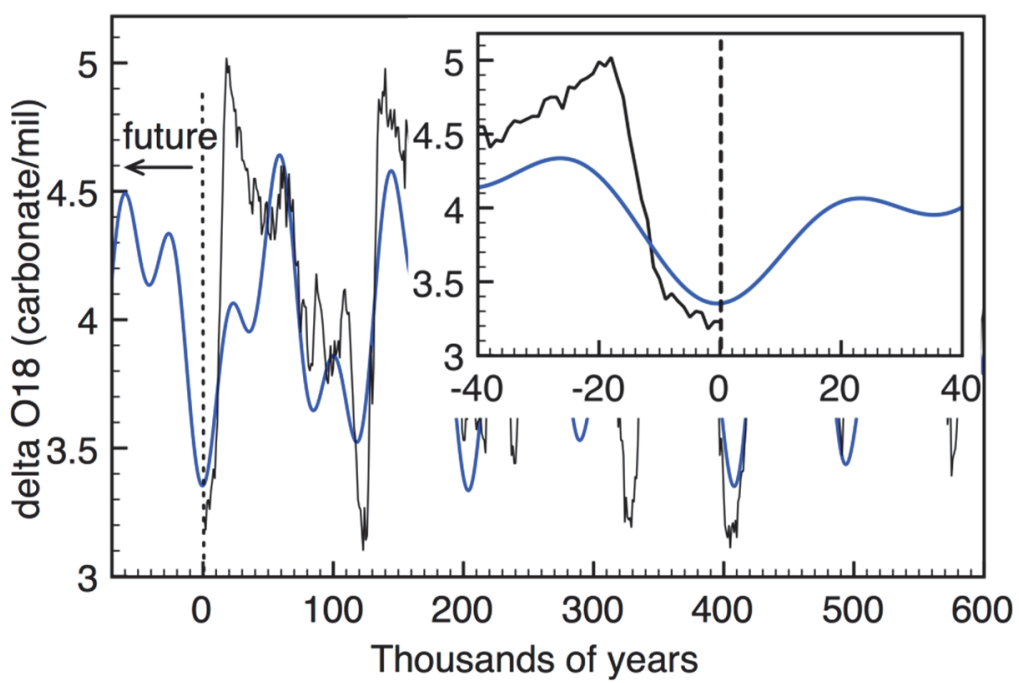

Figure 6. Extrapolation to the next glaciation. Insert is detail of near term climate with time running left to right. 


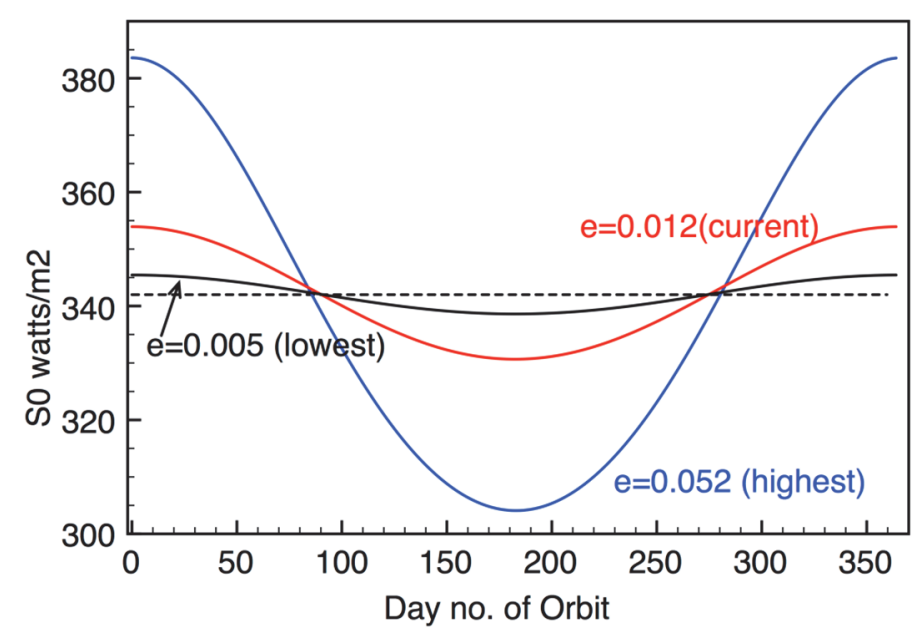

Figure 7. Variation of average solar radiation with orbital ellipticity

\section{References}

Berger, A., Loutre, M. F., \& Melice, J. L. (2006). Equatorial insolation from precession harmincs to eccentricity frequencies, Cli. Past Discuss., 2519.

Berger, A., \& Loutre, M. F. (1994). Precession, eccentricity, obliquity, insolation and paleoclimates NATO ASI Ser., Long-Term Climatic Variations, 122, 107-145.

Gerald, H. H., \& Ralf, T. (1998). Effect of the formation of the Isthmus of Panama on Atlantic Ocean thermohaline circulation. Nature, 393, 673-676.

Hays, J. D., Imbrie, J., \& Shackleton, N. J. (1976). Variations in the Earth's orbit: pacemaker of the Ice Ages. Science, 194, 1121-1132.

Hostetler, S. W., \& Mix, A. C. (1999). Reassessment of ice-age cooling of the tropical ocean and atmosphere. Nature, 399.

John, H. (1994). Global Warming The Complete Briefing, ISBN 0745930255.

Lisiecki, L. E., \& Raymo, M. E. (2005). A Pliocene-Pleistocene stack of 57 globally distributed benthic d18O records. Paleoceanography, 20, PA1003.

Maureen, R., \& Peter, H. (2008). Unlocking the mysteries of the ice ages. Nature, 451(17), 284.

Milankovitch, M. (1941). Canon of Insolation and the Ice Age Problem. Belgrade: Koniglich Serbische Akademie.

Raymo, M. E., Ruddiman, W. F., \& Froelich, P. N. (1988). Influence of late Cenozoic mountain building on ocean geochemical cycles. Geology, 16, 649-653.

Wielicki, B. A., Barkstrom, B. R., Harrison, E. F., Lee, R. B., Smith, G. L., \& Cooper, J. E. (1996). Clouds and the Earth's Radiant Energy System (CERES): An Earth Observing System Experiment. Bull. Amer. Meteor. Soc., 77, 853-868.

Yosef, A., Ian, E., Hezi, G., \& Eli, T. (2010). The Effects of Milankowitz Variations in Insolation on Equatorial Seasonality. J. Climate, 23, 6133.

\section{Note}

Note 1. Concise Dictionary of Physics: Phenomenological Theory. A theory that expresses mathematically the results of observed phenomena without paying detailed attention to their fundamental significance.

\section{Copyrights}

Copyright for this article is retained by the author(s), with first publication rights granted to the journal.

This is an open-access article distributed under the terms and conditions of the Creative Commons Attribution license (http://creativecommons.org/licenses/by/4.0/). 